\title{
REVIEW \\ Analysis of Spatial and Temporal Variation of Soil Organic Carbon Budget in Northern Kazakhstan
}

\author{
Yusuke TAKATA ${ }^{1 *}$ \\ Graduate School of Agriculture, Kyoto University (Sakyou, Kyoto 606-8502, Japan)
}

\begin{abstract}
Farm-regional evaluation of soil organic carbon (SOC) dynamics for the chernozem zone in northern Kazakhstan is now vitally important for making agro-environmental policy. In this study, the author intends to evaluate spatial and temporal variation of the SOC budget and to seek alternative ways of sustainable land use in northern Kazakhstan. To achieve this final goal, this study established the following objectives: to (1) clarify the spatial patterns of soil organic matter content, (2) clarify the influence of land use on the dynamics of soil organic carbon in situ for the three differential soil classes, and (3) clarify spatial and temporal variability of SOC budget in farm-regional scale. The highest SOC content was found in the northern region and the lowest content in the southern region of the study area. Potentially mineralizable carbon (PMC) content, however, was highest in the midwestern region. Furthermore, fluctuations in $\mathrm{CO}_{2}$ emission from the soils showed a similar pattern to temperature fluctuations. Using PMC, soil temperature, precipitation and/or dryness factor, $40-80 \%$ of the variation of $\mathrm{CO}_{2}$ emission could be estimated. From farm-regional evaluation, it is concluded that the spatial and temporal variation of the SOC budget was significantly affected by the crop rotation system in the area. In addition, the fallow- and barley-based crop rotation systems accelerate SOC depletion in the study area.
\end{abstract}

Discipline: Agricultural environment

Additional key words: Chernozem, $\mathrm{CO}_{2}$ emission, geostatistics, MODIS

\section{Introduction}

Central Asia is a unique region among the world's agro-ecosystems, because the drastic changes of land resource management have arisen from major socioeconomic shifts after the collapse of the Soviet Union ${ }^{11}$. Moreover, it is a region that has witnessed some major environmental catastrophes and degradation of its land resources $^{2,7}$. Kazakhstan accounts for around $90 \%$ of the total wheat production area in Central Asia ${ }^{6}$, making it one of the most important regions for global food production. Since fertile Chernozem soils cover northern Kazakhstan, this region produces $70 \%$ of the national cereal production $^{9}$. These soils are also considered to store a substantial amount of soil organic carbon (SOC), functioning as a huge source and sink of atmospheric carbon dioxide $\left(\mathrm{CO}_{2}\right)$. The Chernozem soils in northern Kazakhstan are therefore a vital resource from both agricultural and environmental viewpoints.

The World Bank ${ }^{19}$ reported that the SOC in the agricultural ecosystem in northern Kazakhstan substantially declined during 35 years (1960-1995) after land reclamation. However, farm-regional scale information on the spatial and temporal variation of SOC dynamics and the related factors in northern Kazakhstan is very limited, even though such information is now vitally important for the purpose of making agro-environmental policy.

This paper reports the results obtained in the collaborative project on the "Soil Organic Matter Dynamics in Eurasian Steppe” based on the Agreement between Kyoto University, Japan and Barayev Kazakh Research and Production Center of Grain Farming, Kazakhstan. The research was supported by the Grant-in Aid of Scientific Research (B) of the Ministry of Education, Culture, Sports, Science and Technology, Japan.

Present address:

${ }^{1}$ Natural Resources Inventory Center, National Institute for Agro-Environmental Sciences (Tsukuba, Ibaraki 305-8604, Japan)

*Corresponding author: e-mail takatay@affrc.go.jp

Received 28 July 2009; accepted 21 December 2009. 
Therefore for this reason, farm and region have not been able to proclaim an innovative remedy for preventing SOC depletion.

In this study, the author intends to evaluate spatial and temporal variation of the SOC budget and to seek alternative ways of sustainable land use in northern Kazakhstan. To achieve this final goal, this study established the following objectives:

1) to clarify the spatial patterns of soil organic matter content,

2) clarify the influence of land use on the dynamics of soil organic carbon in situ for the three differential soil classes and

3) clarify spatial and temporal variability of the SOC budget in a farm-regional scale.

\section{Study area}

The main cereal farming areas of the Republic of Kazakhstan, where this study was conducted, are located in the Aqmora and Northern Kazakhstan oblasts. The study area was chosen to include a central area part of both oblasts; 54 $04^{\prime} \mathrm{N} 69^{\circ} 34^{\prime} \mathrm{E}$ and 50 43' N 7049' E in the upper left and lower right corners of the area (Fig. 1a), respectively.

According to local soil classification, the chosen area is characterized by three different soils (Fig. 1b): Ordinary Chernozem (OC), Southern Chernozem (SC) and Dark Chestnut (DC), which are in US Taxonomy correlated to Pachic Haplustolls, Typic Haplustolls and Entic Haplustolls, respectively. In the area, OC is distributed in the lowest altitude zone of the northwest and the highest altitude zone of the west. SC is distributed in the low altitude zone of the north to northeast and the medium altitude zone of medium latitude of this area. DC is distributed only in the southern part of the study area.

The area was characterized by a continental climate with hot summers and cold winters. According to the local meteorological stations, mean annual precipitation ranged from 300 to $360 \mathrm{~mm}$ with large variations among years. Average annual air temperature ranged from 1.5 to $3.2^{\circ} \mathrm{C}$.

A fallow-based crop rotation system is widely spread in the region, and fallow fields could occupy $29 \%$ to $33 \%$ of the area under crop rotation ${ }^{13}$. Fields under fallow are usually mechanically harrowed several times to keep the land bare for protecting against weeds, capturing soil moisture, and nutrient accumulation to accelerate mineralization of soil organic matter. This practice was also commonly applied in the steppe area of North America in which the annual precipitation is below $500 \mathrm{~mm}$. The standard crop rotation in northern Kazakhstan was gen- erally adapted as a fallow with three or four years of continuous small grains cultivation: fallow-wheat-wheat-barley or fallow-wheat-wheat-barley- wheat.

\section{Spatial pattern of soil organic matter content}

Takata et al. ${ }^{15}$ developed a method to improve the accuracy of spatial prediction for soil organic matter status, i.e. potential mineralizable carbon (PMC) and SOC, using secondary information, namely, elevation (ELEV), mean curvature (MEANC), compound topographic index (CTI), and slope (SLOPE) obtained from a digital elevation model, and enhanced vegetation index (VI) values obtained from a Moderate Resolution Imaging Spectroradiometer (MODIS). The prediction methods included statistical (multiple linear regression based on secondary information) and geostatistical (regressionkriging (Model-C) ${ }^{10}$ and simple kriging with varying local means (SKlm) $)^{3}$ ) algorithms.

Soil sampling (518 sites: Fig. 1a) was conducted between May 2003 and August 2005. SOC content of the 518 sites was measured by the Tyurin method, and PMC content of 434 sites was determined by incubating $15 \mathrm{~g}$ soil samples for 19 weeks at an air temperature of $30^{\circ} \mathrm{C}$ and $60 \%$ water field capacity ${ }^{15}$.

To predict soil organic matter, 355 sites for PMC and 458 sites for SOC were utilized. Another group of sample points at different locations $(n=60)$ were used for testing each of the prediction methods; where I computed two indices (the mean error (ME) and the root mean square error (RMSE)) from the observed and predicted values.

For predicting PMC and SOC, the VI, ELEV and MEANC were selected as the independent variables in multi linear regression.

$$
\begin{aligned}
\mathrm{PMC}= & 1.72+4.27 \mathrm{VI}^{* *}-0.001 \mathrm{ELEV}^{* *} \\
& +69.91 \mathrm{MEANC}^{*}\left(\mathrm{n}=355, \mathrm{R}^{2}=0.08\right) \\
\mathrm{SOC}= & 28.45+79.27 \mathrm{VI}^{* *}-0.053 \mathrm{ELEV}^{* *} \\
& -438.04 \mathrm{MEANC}^{*}\left(\mathrm{n}=458, \mathrm{R}^{2}=0.44\right) \\
(* P< & 0.05 ; * * P<0.01)
\end{aligned}
$$

The residuals associated with multi linear regression were useful for taking into account the surrounding measured data to predict PMC and SOC content using regression-kriging. The most appropriate method for predicting spatial pattern of PMC and SOC is SKIm, because the model validity revealed the smallest errors for this method (Table 1).

The highest SOC content was found in the northern region and the lowest content in the southern region of the study area (Fig. 1d). PMC content, however, was highest in the mid-western region (Fig. 1c). It is noteworthy that the highest SOC content zone did not coincide with the highest PMC content zone. In other words, the 


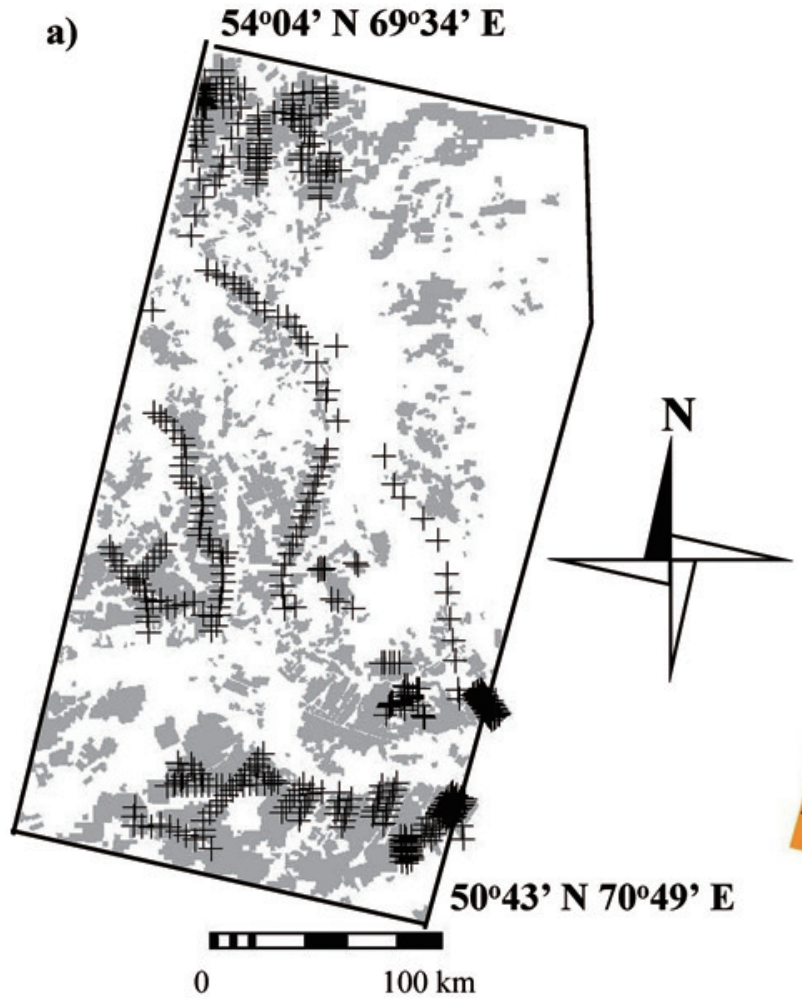

(c)

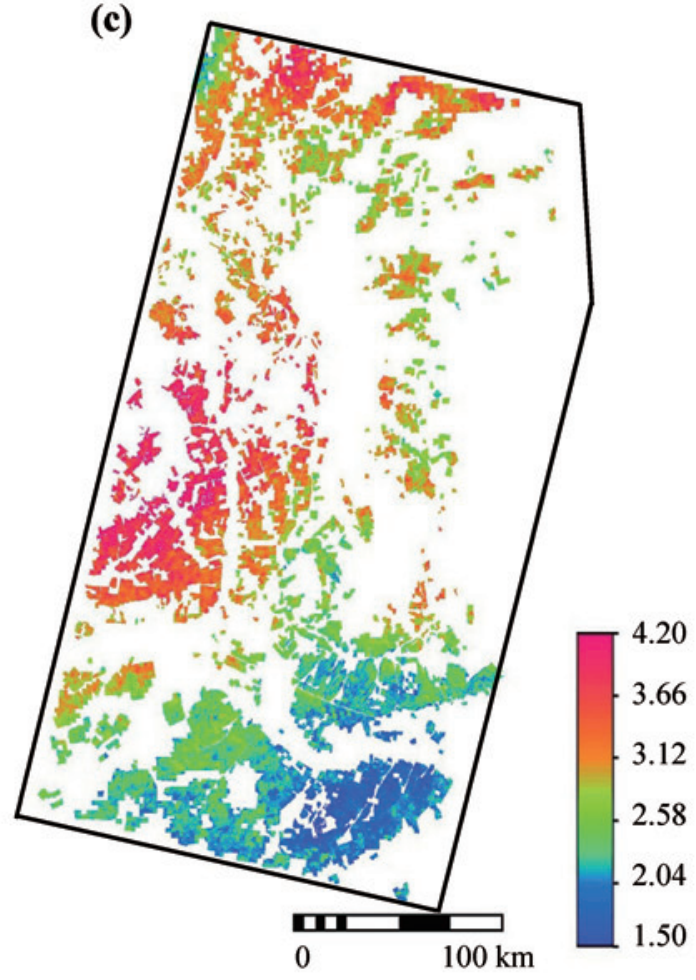

PMC b)

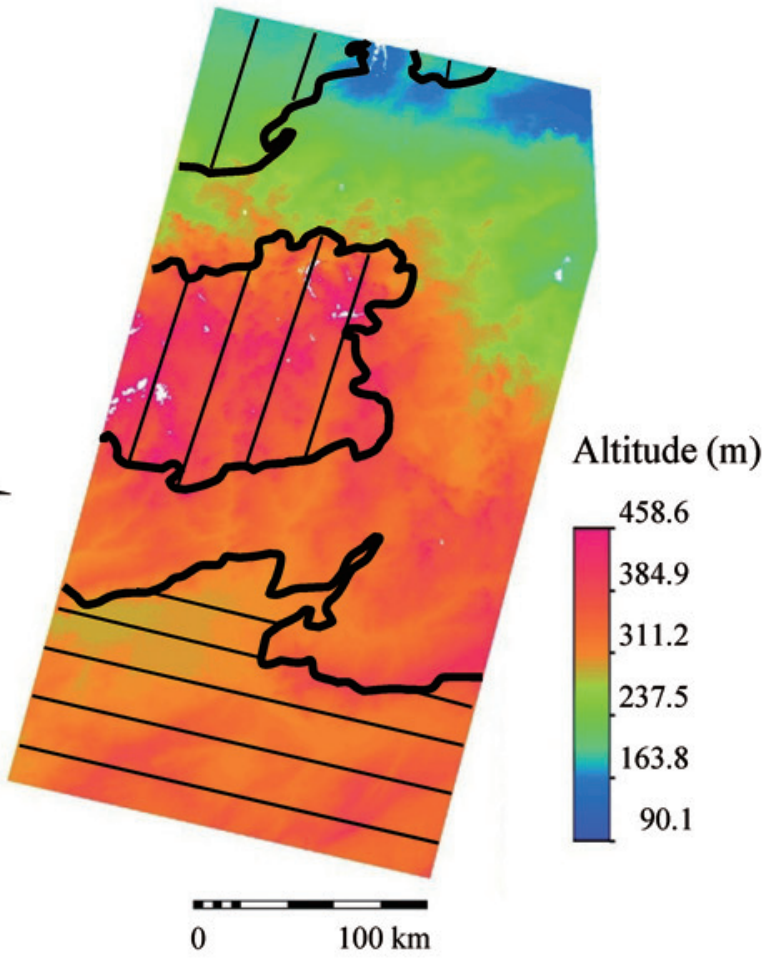

(d)

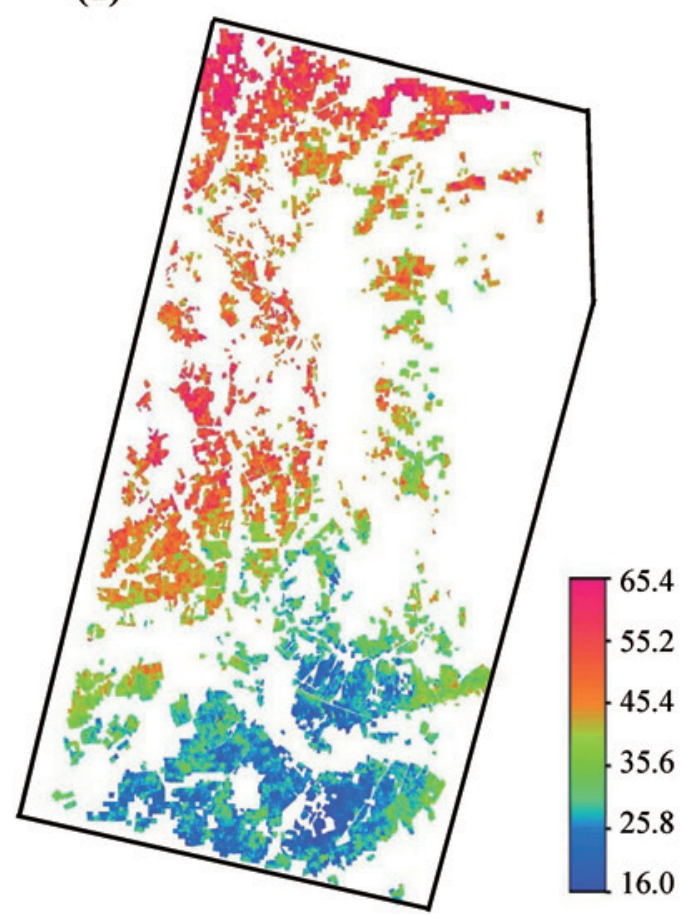

SOC

Fig. 1. Agro-environmental information of the study area

a) is the distribution pattern of cereal cropping and soil sampling points, b) is the topographic and soil map, c) is potentially mineralizable carbon (PMC) content delineated by the SKlm method, and d) is soil organic carbon (SOC) content delineated by the SKIm method (Source: Takata et al..$^{15}$ ).

$\square$ : Cereal cropping fields, + : Soil sampling points,

페 : Ordinary Chernozem, $\square$ : Southern Chernozem, 氖: Dark Chestnut. 
zone which has the largest sink of organic matter did not coincide with the largest source of $\mathrm{CO}_{2}$ on a state level. Conservation of soil organic matter in the highest PMC zones can require more careful land management.

\section{Prediction of $\mathrm{CO}_{2}$ emission}

Takata et al. ${ }^{14}$ studied the influence of land use (cereal field, summer fallow field and meadow fields) on the dynamics of soil organic carbon in situ for the 3 different soil classes (DC, SC and OC) in the area.

$\mathrm{CO}_{2}$ emission was measured by a trenching method (exclusion of root respiration) during the cropping season (May to September) 2002 (SC site only), 2004 and 2005. An alkaline absorption method was used to determine $\mathrm{CO}_{2}$ emission. During the investigation period, respired $\mathrm{CO}_{2}$ was measured about twice a month. At the time of measurement, soil temperature at $5 \mathrm{~cm}$ depth and volumetric water content (\%) at 0-15 cm depth were recorded. Air temperature, soil temperature, soil moisture, and precipitation were monitored in 2002 (SC site), 2004 (OC and SC sites) and 2005 (OC, SC and DC sites) using a micro logger during the cropping season. Due to the economic difficulties involved in monitoring soil water content daily at each site, we introduced a dryness factor, computed by division of precipitation by potential evapotranspiration (PET). Daily PET was estimated using the Hargreaves-Samani equation ${ }^{4,5}$.

Fluctuations in $\mathrm{CO}_{2}$ emission from the soils showed a similar pattern to those of temperature (Fig. 2). Land use markedly influenced the seasonal variation of $\mathrm{CO}_{2}$ emission. To estimate daily $\mathrm{CO}_{2}$ emission, a prediction equation of $\mathrm{CO}_{2}$ emission using stepwise multiple regression of the Arrehenius model was derived from environmental soil factors by soil type and by land use type. Using soil environmental factors, $40-80 \%$ of the total variation of $\mathrm{CO}_{2}$ emission could be estimated (Table 2). Annual $\mathrm{CO}_{2}$ emission is the summation of daily $\mathrm{CO}_{2}$ emission from 1 April to 31 October. Mean annual $\mathrm{CO}_{2}$ emission of cereal fields was estimated to range from 0.75 (DC) to 1.14 (SC) $\mathrm{Mg} \mathrm{C} \mathrm{ha}^{-1}$. This estimated value is the same level as that for the Canadian prairie (de Jong 1974), while it was lower than for Eurasian Chernozem ${ }^{8,18}$. Mean annual $\mathrm{CO}_{2}$ emission of fallow and meadow fields was estimated to range from 0.71 (DC) to 0.92 (SC) $\mathrm{Mg} \mathrm{C} \mathrm{ha}^{-1}$ and from 0.61 (DC) to 1.34 (OC) $\mathrm{Mg} \mathrm{C} \mathrm{ha-1}^{-1}$, respectively. Annual $\mathrm{CO}_{2}$ emission of cereal and meadow fields in 2005 was slightly higher than in 2004 at each site, because precipitation in 2005 was higher than that in 2004, which greatly affected water availability for soil microbes.

\section{Spatio-temporal variation of SOC dynamics in a kolkhoz-scale}

Takata et al. ${ }^{16}$ evaluated the influence of crop rotation and topography on the spatial and temporal variation of the SOC budget under cereal cropping in a kolkhozscale (7,915 ha) located in a SC site.

The study was carried out at Damsa farm, Shortandy, Aqmorinskaya Oblast, from 2001 to 2005. Yanai et al. ${ }^{20}$ and Takata et al. ${ }^{16}$ described the study field in detail. A five-year crop rotation system was grouped into six classes as follows: wheat-based 5-yr cereal (W-5-yr), wheat-based 4-yr cereal with 1-yr fallow, (W-4-yr), barley-based 5-yr cereal (B-5-yr), barley-based 4-yr cereal with 1-yr fallow (B-4-yr), fallow-based (F), and others (O).

Annual carbon input as plant residues was estimated using MODIS satellite images. The Modified Soil Adjusted Vegetation Index (MSAVI $\left.{ }^{12}\right)$, calculated from MOD09GQK and MDY09GQK products, was used for estimating total plant biomass. From the field investigation, harvest index, the ratio of grain yield to total plant biomass, of wheat and barley were $0.326\left(\mathrm{~N}=209, \mathrm{R}^{2}=\right.$ $0.67)$ and $0.429\left(\mathrm{~N}=24, \mathrm{R}^{2}=0.77\right)$, respectively. In addition, carbon contents of wheat and barley residues were $0.396\left(\mathrm{~N}=209, \mathrm{R}^{2}=0.95\right)$ and $0.412\left(\mathrm{~N}=24, \mathrm{R}^{2}=0.98\right)$, respectively. These coefficients were used to calculate the carbon input as plant residues ${ }^{16}$.

The daily $\mathrm{CO}_{2}$ emissions of cereal and fallow fields were firstly estimated using the predicted equation (Table

Table 1. Performance of spatial prediction methods of PMC and SOC (Validation points = 60)

\begin{tabular}{|c|c|c|c|c|c|c|c|c|}
\hline & \multicolumn{2}{|c|}{ Validation points } & \multicolumn{2}{|c|}{ Multiple Regression } & \multicolumn{2}{|c|}{ Model-C } & \multicolumn{2}{|c|}{ SKlm } \\
\hline & Mean $(\mathrm{Mg} \mathrm{C} \mathrm{ha-1)}$ & S.D. & $\mathrm{ME}$ & RMSE & $\mathrm{ME}$ & RMSE & $\mathrm{ME}$ & RMSE \\
\hline PMC & 2.82 & 0.85 & 2.302 & 0.741 & -0.933 & 0.743 & -1.188 & 0.723 \\
\hline SOC & 39.4 & 9.15 & -0.127 & 7.197 & 0.598 & 5.801 & 0.193 & 5.571 \\
\hline
\end{tabular}

Source: Takata et al. ${ }^{15}$. 


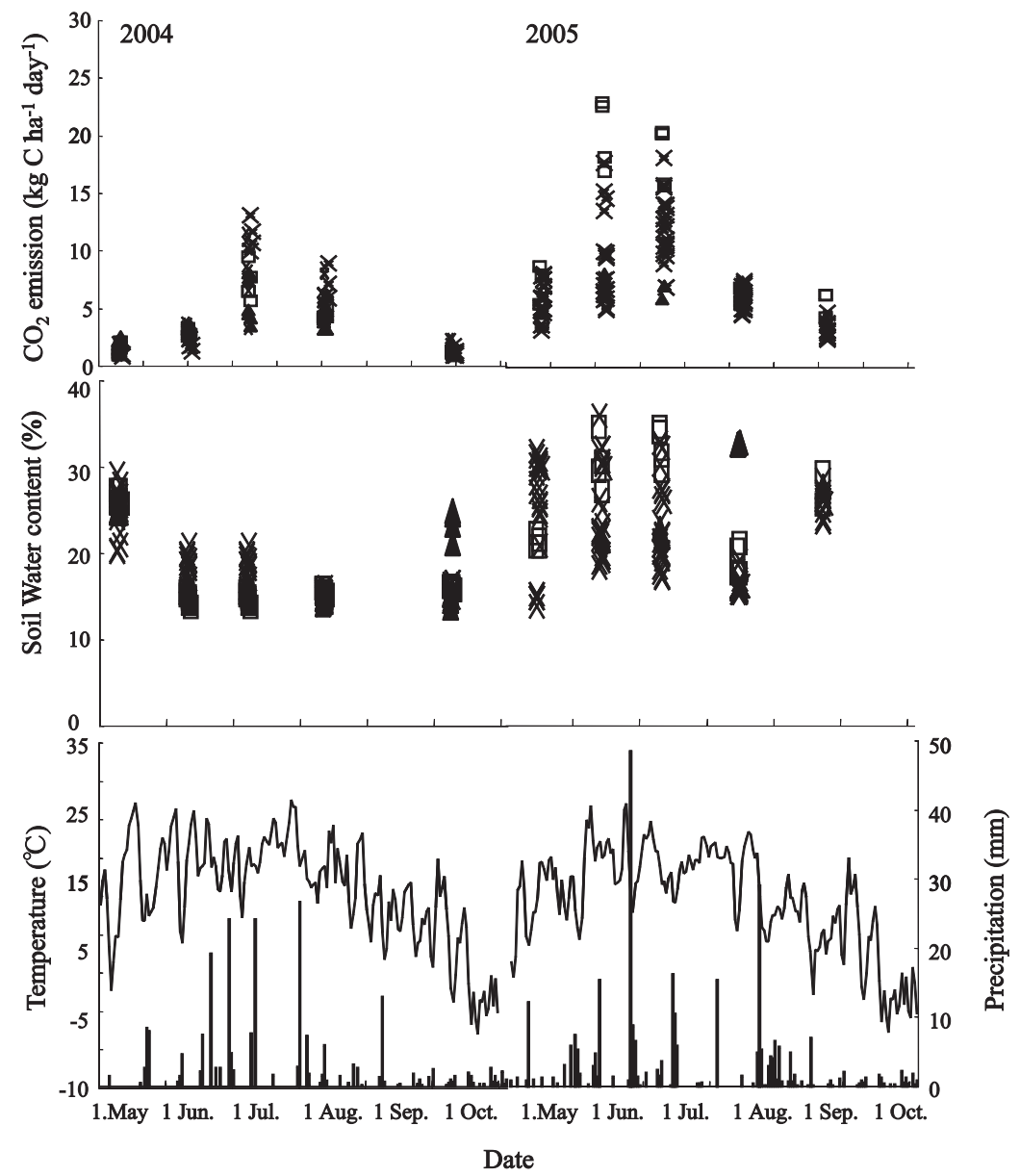

Fig. 2. Daily $\mathrm{CO}_{2}$ emission, soil water content, precipitation, daily mean air temperature, and daily precipitation at $\mathrm{OC}$ site Upper figure shows daily $\mathrm{CO}_{2}$ emission, middle figure shows soil water content and lower figure shows mean air temperature (solid line) and precipitation (rods) (Source: Takata et al..$^{14,15}$ ).

$\times$ : Cereal, $\boldsymbol{\Delta}$ : Fallow, $\square$ : Meadow.

Table 2. Coefficients determined by stepwise multiple regression analysis

\begin{tabular}{|c|c|c|c|c|c|c|c|c|c|c|c|}
\hline \multirow[t]{2}{*}{ Site } & & \multicolumn{7}{|c|}{ Coefficients - } & \multirow{2}{*}{$\mathrm{Q}_{10}\left(10-20^{\circ} \mathrm{C}\right)$} & \multirow{2}{*}{$\mathrm{R}^{2}$} & \multirow{2}{*}{$\mathrm{n}$} \\
\hline & & A & $\mathrm{OM}$ & $\mathrm{b}$ & W & c & Cumulative days & $\mathrm{E}$ & & & \\
\hline \multirow[t]{3}{*}{ DC } & Cereal & $23.05 * *$ & PMC & $0.23^{*}$ & Precipitation & $0.09 * *$ & 8 & $42.47^{* *}$ & 1.81 & $0.62 * *$ & 156 \\
\hline & Fallow & $22.87 * *$ & - & - & Dryness & 0.30 & 15 & $41.42^{* *}$ & 1.79 & $0.49 * *$ & 60 \\
\hline & Meadow & $28.94 * *$ & PMC & $2.63 *$ & Dryness & 0.04 & 8 & $62.04 * *$ & 2.39 & $0.65 * *$ & 34 \\
\hline \multirow[t]{3}{*}{ SC } & Cereal & $25.58 * *$ & PMC & 0.15 & Precipitation & $0.19 * *$ & 15 & $48.31^{* *}$ & 1.97 & $0.40 * *$ & 417 \\
\hline & Fallow & $27.86^{* *}$ & PMC & $0.68 *$ & Dryness & $0.08 * *$ & 9 & $54.38 * *$ & 2.14 & $0.52 * *$ & 51 \\
\hline & Meadow & $29.95 * *$ & - & - & Precipitation & $0.17 * *$ & 10 & $58.81^{* *}$ & 2.28 & $0.65 * *$ & 57 \\
\hline \multirow[t]{3}{*}{ OC } & Cereal & $17.34 * *$ & PMC & $0.33 *$ & Precipitation & $0.54 * *$ & 15 & $31.34 * *$ & 1.55 & $0.83 * *$ & 148 \\
\hline & Fallow & $28.54 * *$ & - & - & Precipitation & 0.15 & 15 & $55.84 * *$ & 2.19 & $0.72 * *$ & 45 \\
\hline & Meadow & $40.83 * *$ & - & - & Dryness & $0.36 * *$ & 15 & $82.53 * *$ & 3.18 & $0.74 * *$ & 38 \\
\hline
\end{tabular}

*, **: Significant at $5 \%$ and $1 \%$ levels, respectively.

$\mathrm{CO}_{2}=\mathrm{AOM}^{\mathrm{b}} \mathrm{W}^{\mathrm{c}} \exp (-\mathrm{E} / \mathrm{RT})$.

$\mathrm{CO}_{2}$ : Daily $\mathrm{CO}_{2}$ emission (mol C ha- ${ }^{-1}$ day $^{-1}$ ).

A: Coefficient $\left(\mathrm{mol} \mathrm{C} \mathrm{ha}^{-1} \mathrm{day}^{-1}\right)$.

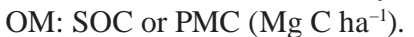

$\mathrm{W}$ : Cumulative precipitation or dryness factor; cumulative days is tested from 2 to 15 days, selected by the highest $\mathrm{R}^{2}$.

E: Activation energy $\left(\mathrm{kJ} \mathrm{mol}^{-1}\right)$.

$\mathrm{R}$ : Gas constant $=8.314\left(\mathrm{~J} \mathrm{~mol}^{-1} \mathrm{~kg}^{-1}\right)$.

T: Soil Temperature (K).

Source: Takata et al. ${ }^{14}$. 
2; SC site). Since $\mathrm{CO}_{2}$ emissions are simulated using PMC, soil temperature, precipitation, and dryness factor, an annual $\mathrm{CO}_{2}$ emission map can be calculated pixel by pixel using PMC, daily soil temperature maps, precipitation maps, and dryness factor maps. The data required for the equation was described by Takata et al. ${ }^{16}$. Then, annual $\mathrm{CO}_{2}$ emission was calculated as the sum of daily $\mathrm{CO}_{2}$ emission from 1 April to 31 October.

The annual carbon budget of all fields was then calculated by subtracting annual $\mathrm{CO}_{2}$ emission from annual carbon input as plant residues.

Annual $\mathrm{C}$ input as plant residues in cereal fields ranged from 1.0 to $1.6 \mathrm{Mg} \mathrm{C} \mathrm{ha-1}$, with higher values in wet years. Annual $\mathrm{CO}_{2}$ emission in cereal fields and fallow fields ranged from 1.0 to $1.2 \mathrm{Mg} \mathrm{C} \mathrm{ha}^{-1}$ and 0.7 to 0.8 $\mathrm{Mg} \mathrm{C} \mathrm{ha}^{-1}$, respectively. In relation to land use, $\mathrm{CO}_{2}$ emission was higher on the north-facing slope than south-facing slope, with the highest values on the higher plateau, and the average annual carbon budget ranged from -0.1 to $0.3 \mathrm{Mg} \mathrm{C} \mathrm{ha}^{-1}$.

The 5-year carbon budgets for the six crop rotation systems, listed in Table 3, ranged from -0.49 (F) to 1.61 (O) $\mathrm{Mg} \mathrm{C} \mathrm{ha}^{-1}$, and the fallow- and barley-based systems were degradative. The $\mathrm{W}-5$-yr system sequestrated considerable amounts of carbon into the soil. The B-5-yr system, in contrast, even when excluding fallow, had a negative carbon budget. Since the variety of the barley seeded in the study area has short stem length as well as drought tolerance, carbon input as barley residues could be lower than those of wheat residues. Thus the B-5-yr and B-4-yr systems had negative carbon budgets. These results indicate that fallow- and barley-based crop rotation systems were depletive.

Table 3. Five-year carbon budget of crop rotation systems

\begin{tabular}{|c|c|c|c|c|c|}
\hline \multirow{3}{*}{$\begin{array}{l}\text { Crop } \\
\text { rotation } \\
\text { system }\end{array}$} & \multirow{2}{*}{$\begin{array}{c}\text { Mean cereal } \\
\text { yield }\end{array}$} & \multicolumn{4}{|c|}{ Carbon budget } \\
\hline & & Ave. & Min. & Max. & $\begin{array}{l}\text { Total carbon } \\
\text { budget }\end{array}$ \\
\hline & $\left(\mathrm{Mg} \mathrm{ha}^{-1}\right)$ & \multicolumn{3}{|c|}{$\left(\mathrm{Mg} \mathrm{C} \mathrm{ha-1}^{-1}\right)$} & $(\mathrm{Mg} \mathrm{C})$ \\
\hline W-5-yr & 1.54 & 0.63 & -1.95 & 2.27 & 1,256 \\
\hline W-4-yr & 1.64 & 0.19 & -1.86 & 3.33 & 725 \\
\hline B-5-yr & 1.67 & -0.43 & -1.65 & 0.52 & -216 \\
\hline B-4-yr & 1.92 & -0.13 & -1.10 & 0.92 & -81 \\
\hline F & 1.67 & -0.49 & -1.95 & 2.72 & -680 \\
\hline $\mathrm{O}$ & - & 1.61 & -0.93 & 3.33 & 1,100 \\
\hline Total & 1.65 & 0.27 & -1.95 & 3.33 & 2,104 \\
\hline
\end{tabular}

Source: Takata et al. ${ }^{16}$.

\section{Regional evaluation of spatio-temporal variation of SOC dynamics}

Takata et al. ${ }^{17}$ assessed the effect of crop rotation system and climatic condition on the spatial and temporal variation of $\mathrm{CO}_{2}$ emission, carbon input as plant residues, and SOC budget at a regional scale in northern Kazakhstan, using satellite images, a geostatistical approach, and simulation models of $\mathrm{CO}_{2}$ emission.

To make a crop rotation map (2001-2005), MODIS $250 \mathrm{~m}, 16$-day composite vegetation index (EVI) products (MOD13Q1) were used in this study. The EVI data could detect the phenological difference among cereal, fallow and perennial grass ${ }^{17}$. Using the EVI data, all ground-checked meadow fields (about 5,000 ha at the SC site) and fallow fields (about 4,000 ha at the SC site) for each year were extracted ${ }^{17}$.

Annual carbon input as plant residues was estimated using MODIS satellite images. Annual $\mathrm{CO}_{2}$ emission was estimated using the predicted equation (Table 2). The procedures are described in Takata et al. ${ }^{17}$ in detail. The annual carbon budget of all fields was then calculated by subtracting annual $\mathrm{CO}_{2}$ emission from annual carbon input.

Annual carbon input as plant residues, annual $\mathrm{CO}_{2}$ emission, and SOC budget during 2001 to 2005 are shown in Figs. 3a, 3b and 3c, respectively. Average annual C input as plant residues in cereal fields ranged from 0.9 (2001) to 1.4 (2002) $\mathrm{Mg} \mathrm{C} \mathrm{ha}^{-1}$, with higher values in wet years. Carbon input as plant residues was higher in the northern part of the area than in the others. Average annual $\mathrm{CO}_{2}$ emission ranged from 0.9 (2004) to 1.1 (2002) $\mathrm{Mg} \mathrm{C} \mathrm{ha-1}$, and it was also higher in wet years than in dry years. Additionally, more $\mathrm{CO}_{2}$ was emitted in the northern part of this area. Accordingly, the average annual carbon budget ranged from -0.2 (2001) to 0.3 (2002) Mg $\mathrm{C} \mathrm{ha}^{-1}$, and showed a negative correlation with air temperature during the crop growing season.

The 5-year results of SOC budget for each crop rotation system are shown in Fig. 4. Five-year crop rotation systems were grouped into three classes as follows: 5-yr cereal cropped without fallow (C5), 4-yr cereal cropped with 1-yr fallow, (F1), and 3-yr cereal cropped with 2-yr fallow (F2). The SOC budget in average for each crop rotation system in the DC, SC and OC zones ranged from -0.79 (F2) to 0.75 (C5) $\mathrm{Mg} \mathrm{C} \mathrm{ha}^{-1},-1.41$ (F2) to 0.33 (C5) $\mathrm{Mg} \mathrm{C} \mathrm{ha}^{-1}$ and -1.08 (F2) to 0.17 (C5) $\mathrm{Mg} \mathrm{C} \mathrm{ha}^{-1}$, and it had a negative correlation with fallow frequency. The $\mathrm{C5}$ system sequestrated considerable carbon into soil for every zone, whereas F1 and F2 systems showed negative SOC budgets, except for F1 in the DC zone. These re- 

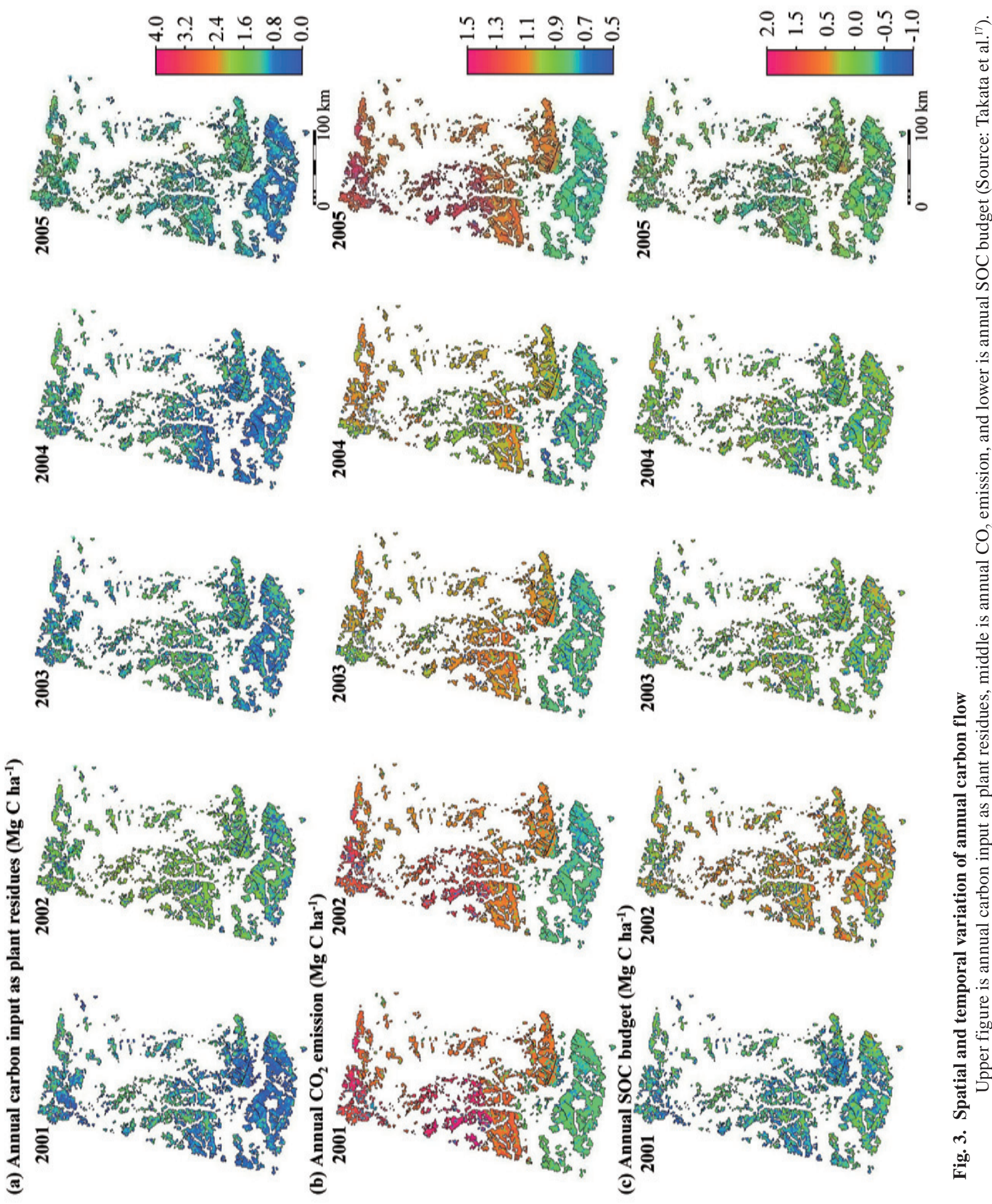


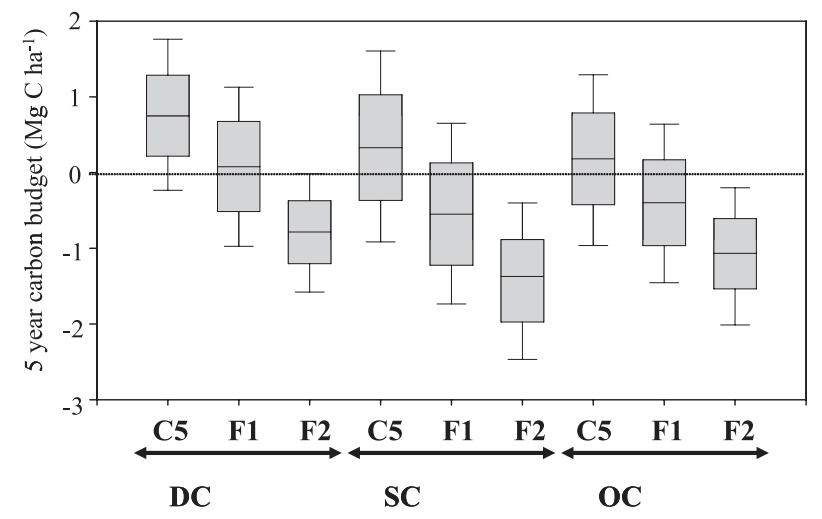

Fig. 4. Box and whisker plots of 5 year soil organic carbon budget

C5 is 5-yr cereal cropped without fallow, F1 is 4-yr cereal cropped with 1-yr fallow and F2 is 3-yr cereal cropped with 2-yr fallow. The first and third quartiles are at the end of the box, the lines end at the upper and lower 5 percentile

(Source: Takata et al. ${ }^{17}$ ).

sults imply that fallow management accelerates SOC depletion across the entire region.

\section{Conclusion}

Although these results include some uncertainty due to the robustness of regression analysis, it is concluded that the spatial and temporal variation of the SOC budget was significantly affected by the crop rotation system in northern Kazakhstan. From the agricultural and environmental viewpoints, summer fallow should be eliminated from the crop rotation system in northern Kazakhstan.

\section{References}

1. de Jong, E. (1974) Soil aeration as affected by slope position and vegetative cover. Soil Sci., 131, 34-43.

2. Glaser, B. et al. (2003) Soil organic matter quantity and quality in mountain soils of the Alay Range, Kyrgyzia, affected by land use change. Biol. Fertil. Soils, 31, 407-413.

3. Goovearts, P. (1997) Geostatistics for natural resource evaluation. Oxford University Press, NY, pp.496.

4. Hargreaves, G.H. \& Samani, Z.A. (1982) Estimating potential evapotranspiration. J. Irrig. Drain. Engr., 108, 223-
230.

5. Hargreaves, G.H. \& Samani, Z.A. (1985) Reference crop evapotranspiration from temperature. Trans. ASAE, 1, 9699.

6. International Maize and Wheat Improvement Center (2002) World wheat overview and outlook 2000-2001. CIMMYT, Texсосо, Mexico.

7. Lal, R. (2004) Carbon sequestration in soils of central Asia. Land Degrad. Develop., 15, 563-572.

8. Larionova, A.A. et al. (1998) Soil respiration and carbon balance of gray forest soils as affected by land use. Biol. Fertil. Soils, 27, 251-257.

9. Nobe, K. (2000) The agriculture of Kazakhstan during shifting socio-economic systems. Nogyo sogo kenkyu ( $Q$. J. Agric. Econ.), 54, 1-111 [In Japanese].

10. Odeh, I.O.A., McBratney, A.B. \& Chitteleborough, D.J. (1995) Further results on prediction of soil properties from attributes: heterotopic cokriging and regression-kriging. Geoderma, 67, 215-226.

11. Pauw, E.D. (2007) Principal biomes of Central Asia. In Climate change and terrestrial carbon sequestration in central Asia, eds. Lal, R. et al., Taylor and Francis, London, UK, 3-24.

12. Qi, J. et al. (1994) A modified soil adjusted vegetation index. Remote Sens. Environ., 48, 119-126.

13. Shiyatiy, E. (1996) Improvement of soil conserving measures - the base for progress in crop production. In Proceedings of KRIGF: Soil conserving cropping system Problems and outlook, eds. Eskov, A. \& Shiyatiy, E., Shortandy, Kazakhstan, 20-33 [In Russian].

14. Takata, Y. et al. (2007a) Influence of land use on the dynamics of soil organic carbon in northern Kazakhstan. Soil Sci. Plant Nutr., 53, 162-172.

15. Takata, Y. et al. (2007b) Spatial prediction of soil organic matter in northern Kazakhstan based on topographic and vegetation information. Soil Sci. Plant Nutr., 53, 289-299.

16. Takata, Y. et al. (2008a) Influence of crop rotation system on the spatial and temporal variation of soil organic carbon budget in northern Kazakhstan. Soil Sci. Plant Nutr., 54, 159-171.

17. Takata, Y. et al. (2008b) Regional evaluation of spatio-temporal variation of soil organic carbon dynamics for rainfed cereal farming in northern Kazakhstan. Soil Sci. Plant Nutr., 54. 794-806.

18. Vugakov, P.S. \& Popova, Y.E.P. (1968) Carbon dioxide regime in soils of the Krasnoyarsk forest steppe. Sov. Soil Sci., 795-801.

19. World Bank (2003) Kazakhstan drylands management project. Project proposal document, World Bank Report No. 25929-KZ.

20. Yanai, J. et al. (2005) Spatial variability of organic matter dynamics in semi-arid croplands in northern Kazakhstan. Soil Sci. Plant Nutr., 51, 261-269. 